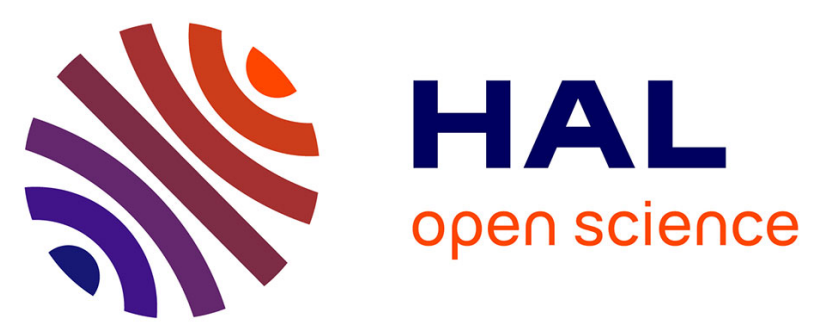

\title{
Situational Flexibility of In-Group-Related Attitudes: A Single Category IAT Study of People with Dual National Identity
}

Gerd Bohner, Frank Siebler, Roberto González, Andrés Haye, Eike A. Schmidt

\section{- To cite this version:}

Gerd Bohner, Frank Siebler, Roberto González, Andrés Haye, Eike A. Schmidt. Situational Flexibility of In-Group-Related Attitudes: A Single Category IAT Study of People with Dual National Identity. Group Processes and Intergroup Relations, 2008, 11 (3), pp.301-317. 10.1177/1368430208090644 . hal-00571689

\section{HAL Id: hal-00571689 \\ https://hal.science/hal-00571689}

Submitted on 1 Mar 2011

HAL is a multi-disciplinary open access archive for the deposit and dissemination of scientific research documents, whether they are published or not. The documents may come from teaching and research institutions in France or abroad, or from public or private research centers.
L'archive ouverte pluridisciplinaire HAL, est destinée au dépôt et à la diffusion de documents scientifiques de niveau recherche, publiés ou non, émanant des établissements d'enseignement et de recherche français ou étrangers, des laboratoires publics ou privés. 


\title{
Situational Flexibility of In-Group-Related Attitudes:
} A Single Category IAT Study of
People with Dual National Identity

\author{
Gerd Bohner \\ University of Bielefeld

\section{Frank Siebler} \\ University of Tromsø
}

\section{Roberto González and Andrés Haye \\ Pontificia Universidad Católica de Chile}

\section{Eike A. Schmidt}

Heinrich-Heine-University of Düsseldorf

\begin{abstract}
An experiment was conducted to examine the situational flexibility of in-group-related attitudes at the implicit and explicit level. Seventy-one men and women with dual, Turkish-German, national identities were asked to think about positive aspects of either their German or their Turkish identity. Later, attitudes toward Germans and Turks were assessed using a single category implicit association test (SC-IAT) and self-report scales. Results showed that attitudes toward Turks were generally more positive than attitudes toward Germans, that SC-IAT scores reflecting attitudes toward Turks and Germans were unrelated, and that the identity priming affected men's, but not women's, SC-IAT scores. This finding is discussed in terms of men's greater flexibility in national identification. Explicit attitude measures were largely unaffected by the priming.
\end{abstract}

KEYWORDS Germany, immigration, in-group attitudes, national identity, single category implicit association test (SC-IAT), Turks

RESEARCHERS have devoted much attention to intergroup relations and how the social context influences phenomena such as in-group favoritism and out-group derogation (for a review, see Hewstone, Rubin, \& Willis, 2002). Much less is known, however, about the way in which the context might influence people's

\section{Author's note}

Address correspondence to Gerd Bohner, Abteilung für Psychologie, Universität

Bielefeld, Postfach 100131, 33501

Bielefeld, Germany

[email: gerd.bohner@uni-bielefeld.de] 
attitudes toward the various in-groups they belong to. In the present research, we studied people who hold dual national identities, examining attitudes toward each of their national ingroups and the responsiveness of these attitudes to experimental variations of identity salience. In doing so, we used a recently developed single category measure of implicit attitudes (Karpinski \& Steinman, 2006; Wigboldus, Holland, \& van Knippenberg, 2006), applying this for the first time to the separate assessment of two in-group attitudes. Before presenting our experiment, we briefly describe our target population (Turks in Germany), consider the benefits and limitations of a dual identity, then review conceptualizations of implicit and explicit attitudes, derive hypotheses about their malleability, and speculate about potential gender effects. Finally, we describe the single category measure and discuss its potential for the present research.

\section{Turks in Germany}

Turkish immigration to Germany dates back to the 1960s, when West Germany began recruiting workers from abroad. Although the recruitment of workers from Turkey was officially terminated in 1973, the Turkish population in Germany as a whole kept growing, mainly because a policy of family reunion allowed migrant workers' spouses and children to immigrate (Şen, 1999; Şen \& Wierth, 1992). Today, more than two million people of Turkish origin live in Germany, whose current overall population is 82 million. More than 600,000 Turks have acquired German citizenship (Beauftragte der Bundesregierung für Migration, Flüchtlinge und Integration, 2004). The participants in our study were adults who identify themselves as both Turkish and German, usually because of a family migration background.

\section{Dual identities}

People who embrace two cultural or national identities ${ }^{1}$ present an intriguing case for researchers of social identity. On the one hand, they can be viewed as possessing a valuable resource that may foster flexibility in accommodating to varying social contexts. The benefits associated with a dual identity for promoting positive intergroup attitudes have been widely documented. A dual identity approach appears especially attractive for minority group members who may resist a superordinate identity if accepting that identity means that their own distinctiveness will be lost (see e.g. Berry, 1984, 1999; González \& Brown, 2003, 2006; Hornsey \& Hogg, 2000). On the other hand, a dual identity may also entail a degree of ambivalence, and the experience of 'sitting on the fence' between cultures (see e.g. Berry, Phinney, Sam, \& Vedder, 2006). For German Turks, the ambivalence may be pronounced because of their need to deal with identities grounded in dramatically different cultures, one more collectivist and with a strong Muslim tradition, the other more individualist and secular.

\section{Implicit and explicit group-related attitudes}

To measure group-related attitudes, researchers have been using both explicit and implicit measures, and the two often do not correlate highly. This may be so because some phenomena of social identity and intergroup attitudes operate at an unconscious level, yielding attitudes (or evaluative associations) that are not amenable to conscious introspection and self-report, whereas others are more deliberate and reflective (e.g. Strack \& Deutsch, 2004). Implicit and explicit measures would thus tap two different types of attitude that may coexist in a person's cognitive system (e.g. Wilson, Lindsey, \& Schooler, 2000). A less extensive implicit-explicit definition does not presuppose different types of attitude, but instead refers only to the measures being used: an implicit measure of attitude provides an estimate of a person's attitude without the researcher having to ask for a self-report of that (same) attitude (cf. Webb, Campbell, Schwartz, Sechrest, \& Grove, 1981). Differences between implicit and explicit measurement would then reflect that people may be reluctant to admit on the self-report measure what the implicit measurement reveals about their attitudes. Thus, 
whenever respondents are motivated to distort their attitudes in a self-report, implicit measures may help to gain a more accurate understanding of attitudinal dynamics (for further discussion, see Fazio \& Olson, 2003).

A conceptual distinction between implicit and explicit attitudes (for a review, see Hofmann, Gawronski, Gschwendner, Le, \& Schmitt, 2005) may rely on different sources of each type of attitude (Rudman, 2004). Three of the sources discussed by Rudman may be particularly relevant to our present research: implicit attitudes seem to be caused by early (vs. recent) experiences (e.g. Rudman \& Heppen, 2003), affective (vs. cognitive) experiences (e.g. Rudman, Ashmore, \& Gary, 2001), and the cultural milieu (e.g. Haye et al., 2007; Rudman et al., 2001). Each of these factors points to the possibility that experiences in a person's family of origin may shape implicit group-related attitudes, whereas explicit grouprelated attitudes may be the result of more recent, cognitive learning.

Other research has shown, however, that implicit group-related attitudes may be highly context-sensitive. For examples, they are subject to priming effects (Dasgupta \& Greenwald, 2001 ) as well as variations in focus of attention (Wittenbrink, Judd, \& Park, 2001; for a review, see Blair, 2002). More generally, implicit measures have been shown to capture both stable individual differences and occasion-specific variance (Schmukle \& Egloff, 2006). It therefore seems useful to study both implicit and explicit attitudes in order to explore the contextual malleability of attitudes, especially in a domain where little previous research is available.

\section{Malleability of implicit and explicit group attitudes}

We assumed that, despite their dual identities, our target population's Turkish identity would generally be more prominent, because it is grounded in their culture of origin (see González \& Brown, 2003; Rudman, 2004). Furthermore, membership in a minority group is particularly salient in a person's self-concept. In open-ended self-descriptions, research participants were more likely to spontaneously refer to their own gender or ethnicity if they belonged to the numerical minority on that dimension; this has been demonstrated with both chronic (McGuire, McGuire, Child, \& Fujioka, 1978) and transient (Cota \& Dion, 1986) minority status.

Extending these findings to people with both Turkish and German identities, we might expect their Turkish (minority) identity to have a greater impact on self-related judgment than their German (majority) identity. Also, to the extent that people are motivated to hold positive attitudes toward their ingroups (Tajfel \& Turner, 1986), the chronically greater salience of Turkish identity should produce a chronically more positive attitude toward Turks (vs. Germans). These expectations are in line with findings that group-related attitudes and stereotypes are often rather difficult to change (see Fiske, 1998). However, according to a current conceptualization, attitudes may be understood as temporary construals that change with the context in which they are made (Schwarz \& Bohner, 2001). If so, then it should be possible to reverse the relative impact of a person's minority and majority identities on judgment by subtle variations of the judgment context. In the present research, we primed positive aspects of either the Turkish or the German identity of people identifying with both nations; the priming procedure was aimed at temporarily either increasing or removing any chronic advantage in salience that a minority group membership may have.

\section{Sex differences in flexibility of identification?}

We were also interested in potential sex differences in the flexibility of national identification. In Turkey, as in other countries with a Muslim tradition, the relative status of women is lower than in Germany (see e.g. United Nations, 2005, pp. 304-306). Females growing up in a Turkish family in Germany are thus likely to be educationally restricted more than males, which may prevent females from 'trying out' cultural flexibility. As a result, Turkish men may both objectively have greater experience and subjectively feel more at ease 'switching' 
between cultures, compared to Turkish women (for related results with Turkish immigrants in Canada, see Ataca \& Berry, 2002).

In a similar vein, the social psychological literature on gender differences in self construal suggests that men construct and maintain a more independent (vs. interdependent) selfconstrual compared to women (Cross \& Madson, 1997). Although men's behaviors are designed to form connections with other people as well, they do so in a broader social sphere. Whereas women's sociality is oriented toward dyadic close relationships, men's sociality seems to be oriented toward a larger group (Baumeister \& Sommer, 1997; see also Sidanius, Pratto, \& Rabinowitz, 1994).

Other data, however, suggest an opposite conclusion about sex differences. There is evidence that among second-generation Turkish immigrants, females tend to be more fluent in German, and reach higher education levels and better results than males (Polat, 1998). Although the females' apparently stronger focus on school work may be seen as an indirect consequence of their restricted freedom to engage in other activities, it may also reflect greater motivation on the part of females compared to males to integrate themselves into German culture. This latter interpretation would be in line with Polat's finding that female immigrants were more likely than male immigrants to endorse a 'bicultural' (vs. 'Turkish') social identity (see also S.en, 1999). Overall, the literature thus points to opposing possibilities regarding men's and women's situational flexibility of identification with their Turkish and German ingroups; these were also explored in the current research.

\section{Assessment of implicit group attitudes with a single category measure}

The most popular implicit measure in recent years has been the implicit association test (IAT; Greenwald, McGhee, \& Schwartz, 1998). In the IAT, participants use two keys on the computer keyboard to categorize exemplars of four categories that appear on the screen: two target categories (e.g. German names vs. Turkish names) and two evaluative poles (e.g. positive vs. negative words). In critical trial blocks, one target category and one evaluative category share the same response key. If, in our example, a participant responds faster if German names and positive words share a key than if Turkish names and positive words share a key, this is taken to indicate a relative implicit preference for Germans over Turks. Despite its usefulness in many domains (see Greenwald, 2001; Nosek, Greenwald, \& Banaji, 2006), a limitation of the IAT is that it allows one to measure only relative attitudes toward pairs of attitude objects (e.g. Germans vs. Turks, but not simply attitudes toward Germans). This poses a problem in intergroup research, where it can be conceptually useful to treat in-group and out-group evaluations as separate variables. In-group favoritism and out-group derogation can be asymmetrical, and one process does not necessarily implicate the other (see e.g. Mummendey \& Otten, 1998). Studying similar asymmetries at the implicit level would be impossible with a standard IAT (see also Siebler et al., 2007). For our present research, it also seemed vital to assess implicit attitudes toward Germans and Turks not only in terms of a bipolar, relative comparison, but also as independent constructs. Assuming that people would not normally derogate either of their in-group identities, a standard IAT might create an artificial bipolarity in the assessment process.

We therefore used a variant of the IAT that was designed for the assessment of implicit attitudes toward single targets. Two groups of researchers have independently proposed a conceptually identical instrument, called 'singletarget IAT' (Wigboldus et al., 2006) or 'single category IAT' (SC-IAT; Karpinski \& Steinman, 2006). Its main modification of the standard IAT consists of trial blocks in which stimuli representing only one target category (e.g. either Turkish names or German names) share a key with an evaluative concept (e.g. positive words), whereas the other key is used to respond only to evaluative concept stimuli (e.g. negative words). By comparing response latencies between blocks where the target category is paired with positive 
stimuli and blocks where the target category is paired with negative stimuli, a single-category implicit evaluation score can be computed (see Method section for further detail). In our current research we used SC-IATs measuring unipolar implicit evaluations of Germans and Turks, respectively, followed by standard IAT blocks measuring bipolar implicit evaluations of Turks versus Germans (cf. Karpinski \& Steinman, 2006; Wigboldus et al., 2006).

Research has shown that the SC-IAT is useful in locating the origin of in-group-out-group differences in implicit evaluation: Karpinski and Steinman (2006, Study 3) found that Whites' significant pro-White scores on a standard BlackWhite race IAT reflected in-group favoritism (as indicated by a positive White SC-IAT score) but not out-group derogation (as indicated by a neutral Black SC-IAT score). To our knowledge, however, there have been no studies using the SC-IAT for assessing separate implicit evaluations of different in-groups. As outlined above, we believe that the dual-identity paradigm is ideal for further highlighting the limitations of the standard IAT and demonstrating the usefulness of the SC-IAT in studying in-group attitudes per se. Also, our present study was the first to apply an experimental variation of identity salience to examine the contextual malleability of SC-IAT scores.

\section{Summary of hypotheses and exploratory research questions}

Based on the above discussion, we formulated two hypotheses. Hypothesis 1: German Turks' attitudes towards Turks will be more positive overall than their attitudes towards Germans. Hypothesis 2: Attitudes towards Turks (Germans) will be positively affected by the priming of positive aspects associated with being Turkish (German). In addition, we explored sex differences in responsiveness to the priming without committing ourselves to a directional hypothesis.

In principle, our hypotheses pertain to both explicit and implicit attitudes. Whether effects of identity priming and potential sex differences would be stronger for implicit or for explicit measures was an open question. On the one hand, implicit measures may be more affected, because they are free from the mitigating effects of selfpresentation or subjective norms (e.g. 'I ought to honor my Turkish heritage'). On the other hand, implicit measures may be less affected because they tap deeply ingrained, core associations (Rudman, 2004; Wilson et al., 2000), and only part of their variance may reflect situational influences (Schmukle \& Egloff, 2005).

\section{Method}

\section{Participants}

Participants were recruited for a study on 'Turkish/German dual national identity' at the University of Bielefeld and at locations where one was likely to encounter people from our target population (e.g. a Turkish community center). Subjectively having both Turkish and German national identities was a prerequisite for participation, but there were no formal requirements regarding citizenship. The sample consisted of 71 adults (40 female, 31 male; mean age 25.7 years), who were all residents of Germany. Self-reported citizenship was roughly representative of Turks in Germany (only Turkish: 42; only German: 25; both Turkish and German: 4). Sixty-four participants indicated that their parents were Turkish, and 33 had Turkish partners. Each participant was paid 5 euros.

\section{Procedure and design}

The study was run on notebook computers by an experimental program written in Visual Basic. Participants were randomly assigned to one of two identity priming conditions (Turkish vs. German). They were asked, depending on condition, to think about either their Turkish or their German identity and to type into several boxes what they thought was positive about being Turkish (or German, respectively), listing one thought per box. After this thought-listing task, they completed either the implicit or the explicit attitude measures (see below). Then they were shown the thought listing screen again, including the thoughts they had entered earlier, and given an opportunity to add further thoughts if they so wished. This was done to refresh the identity priming manipulation before 
moving on to the remaining attitude measures. Participants who had first completed the implicit measures now completed the explicit measures, and vice versa. Later, participants reported their sex, age, occupation, and nationality, their parents' nationality, and (where applicable) their partner's nationality. At the end of the session they were thanked for their participation, were paid and debriefed.

\section{Implicit attitude measures}

Overview In the SC-IAT section of the study, participants responded to stimulus words on the computer screen by pressing one of two dedicated keys on the computer keyboard. Stimuli were Turkish and German first names, as well as positive and negative nouns. We collected three measures: (a) an SC-IAT score indicating the implicit evaluation of the concept Turkish (Turkish SC-IAT), (b) an SC-IAT score indicating the implicit evaluation of the concept German (German SC-IAT), and (c) a standard IAT score indicating the relative implicit evaluation of the concept Turkish as compared to the concept German (standard IAT).

Selection of stimulus words To represent the concepts Turkish and German, respectively, we used five Turkish first names (Ali, Bülent, Feramis, Mustafa, Mehmet) and five German first names (Ferdinand, Jürgen, Max, Michael, Werner), which were roughly matched for familiarity, initial letter, and length. Evaluative concepts were represented by 10 positive nouns (Begeisterung [enthusiasm], Blume [flower], Entspannung [relaxation], Frieden [peace], Freude [joy], Gesundheit [health], Glück [luck/happiness], Heiterkeit [cheeriness], Liebe [love], Spaß [fun]), and 10 negative nouns (Ärger [anger], Elend [misery], Hass [hate], Krankheit [illness], Krieg [war], Panik [panic], Schmerz [pain], Tod [death], Unglück [misfortune], Verrat [treason]), which, in a pilot test, were shown to differ significantly from the scale midpoint in the intended direction on a scale from negative (1) to positive (7), but not to differ from the scale midpoint on a scale from Turkish (1) to German (7). To familiarize participants with these materials, the SC-IAT started with the presentation of the complete stimulus lists.

Trial blocks Participants responded to 20 stimulus words in each of seven trial blocks (see Table 1 for an overview). Because of restrictions of the field setting, we used a smaller number of trials than is usually employed in laboratory research (cf. Karpinski \& Steinman, 2006). Each stimulus word was shown once within a given block. Incorrect responses were signaled by the computer and had to be corrected. Within blocks, stimuli were presented in a random order, with an inter-stimulus interval of $500 \mathrm{~ms}$. Block 1 served as a practice block. Participants

Table 1. Sequence of blocks in the SC-IAT

\begin{tabular}{lll}
\hline & \multicolumn{2}{c}{ Key assignment of stimuli (example) } \\
\cline { 2 - 3 } Block number and description & Left & Right \\
\hline 1. Attribute discrimination block & 'pleasant' & 'unpleasant' \\
2. SC block, first target positive & 'pleasant or German' & 'unpleasant' \\
3. SC block, first target negative & 'pleasant' & 'unpleasant or German' \\
4. SC block, second target positive & 'pleasant or Turkish' & 'unpleasant' \\
5. SC block, second target negative & 'pleasant' & 'unpleasant or Turkish' \\
6. Standard IAT block 1 & 'pleasant or Turkish' \\
7. Standard IAT block 2 & 'pleasant or German' & 'unpleasant or German' \\
\hline
\end{tabular}

Notes: The following variables were fully counterbalanced: (1) left vs. right assigment of 'pleasant' and 'unpleasant' stimuli (this remained constant across blocks within each condition), (2) German vs. Turkish representing the first target assessed in blocks 2 and 3, and (3) first target paired first with positive vs. negative items. The key assignments in the two rightmost columns thus represent one example that may be used as a template to reconstruct all eight versions. $\mathrm{SC}=$ single category; IAT = implicit association test. 
discriminated between pleasant and unpleasant words by pressing either the left-hand or the right-hand response key, as indicated by labels appearing at the top of the computer screen.

Blocks 2 to 5 represented the SC-IAT blocks. In Block 2, stimuli representing one of the target concepts (e.g. German) were shown in addition. They required the same response as one of the evaluative concepts (e.g. pleasant). Thus, participants pressed one response key if the stimulus represented either the target concept or the evaluative concept associated to it in the present block (e.g. pleasant or German), but pressed the other key if the stimulus represented the remaining evaluative concept (e.g. unpleasant). In Block 3, stimuli from the same target concept as in the previous block were shown, but shared the response key with the opposite evaluative concept. The difference in the average response time per trial between Blocks 2 and 3 was defined as a participant's single category IAT score for that target concept. Blocks 4 and 5 were similar to the preceding two blocks, but replaced the first target concept with the second one. As before, the difference in mean response times between Blocks 4 and 5 was defined as the single category IAT score toward the second target.

Blocks 6 and 7 represented standard IAT blocks. Stimulus words from all four categories were assigned to responses such that one of the target concepts shared a response key with one of the evaluative concepts, whereas the other target concept shared a response key with the other evaluative concept. For instance, in Block 6, participants may have been asked to press the left-hand key in response to pleasant or Turkish stimuli, and to press the right-hand key in response to unpleasant or German stimuli. Importantly, the assignment of target concepts to evaluative concepts was then reversed in Block 7 . The difference in average response times between Blocks 6 and 7 defined a participant's standard IAT score, i.e. a relative preference for one target concept over the other. ${ }^{2}$

Computation of response time data Response times of less than $300 \mathrm{~ms}$ or more than $3000 \mathrm{~ms}$ were recoded into these boundary values (see
Greenwald et al., 1998). Blockwise mean response times were then computed for correct responses. For the SC-IAT scores, we subtracted the average latency of the block where the target concept shared a response key with positive nouns from the average latency of the block where the target concept shared a key with negative nouns. Thus, positive (negative) Turkish SC-IAT scores indicate a positive (negative) implicit evaluation of Turks, and positive (negative) German SCIAT scores indicate a positive (negative) implicit evaluation of Germans. The standard IAT was scored such that positive (negative) scores indicate a relative preference for Turks over Germans (Germans over Turks).

Reliability Response errors and extreme response times (above $3000 \mathrm{~ms}$ or below $300 \mathrm{~ms}$ ) occurred only rarely ( $6 \%$ and $3 \%$, respectively). The internal consistency (odd-even reliability estimates based on the Spearman-Brown formula) was acceptable for the German SC-IAT $\left(r_{t t}=.60\right)$ and the Turkish SC-IAT $\left(r_{t t}=.64\right)$, but rather modest for the standard IAT $\left(r_{t t}=.32\right)$. The latter result may partly be explained by the small number of trials (see below for further discussion).

\section{Explicit attitude and identification measures}

Explicit attitudes were assessed with a variety of scales tapping evaluative beliefs and feelings about each of the nationality groups. Furthermore, the perceived status of and identification with each national group were assessed with several items.

Relative status and identification We assessed the perceived relative status of the two nationality groups using two bipolar items: 'Which group generally enjoys a higher reputation?' and 'Which group generally has more influence?' (1 the Germans, 7 the Turks). Responses were averaged to form an index of perceived relative status $(\alpha=.58)$. Three items referred to identification with each nationality: 'How much do you consider yourself to be Turkish (German)?', 'How much do you enjoy being Turkish (German)?', and 'How important is it for you to be Turkish 
(German)?' (1 not at all, 7 very). Responses were averaged for each target group (Turks: $\alpha=.75$; Germans: $\alpha=.79)$. Three further items were averaged to assess the relative identification with Turkish versus German nationality along a single bipolar dimension: 'Where would you like to live after retirement?', 'Where would you like to be buried/cremated?', and 'When there is a sports competition between Germany and Turkey, which team do you normally support?' (1 definitely Turkey, 7 definitely Germany; $\alpha=.63$ ).

Prejudice Explicit prejudices toward Turks and Germans were measured with three items taken from Pettigrew and Meertens' (1995) prejudice scale: 'In principle, I could imagine myself having children with a German (Turk)'; 'In principle, I could imagine having a sexual relationship with a German (Turk)'; 'I would not mind if a German (Turk) married into my family' (1 strongly disagree, 7 completely agree). Responses were averaged for each target group (Turks: $\alpha=.64$; Germans: $\alpha=.72$ ) and recoded so that higher scores on these measures indicate greater prejudice.

Evaluation Another explicit evaluation measure consisted of five items for each target group: 'How much do you like (admire / trust / respect/ like to cooperate with) Germans (Turks)?' (1 not at all, 7 very much). Responses were averaged for each target group (Turks: $\alpha=.80$; Germans: $\alpha=.80)$.

Stereotyping Stereotyping of Germans and of Turks was each measured with 16 adjective items that had been derived from a larger list. ${ }^{3}$ Eight positive (e.g. hospitable, dependable) and eight negative items (e.g. aggressive, cold) were presented twice, once referring to Turks and once referring to Germans ( 1 does not apply at all, 7 applies exactly). To obtain commensurable stereotyping indices, we combined all eight positive and all eight negative items, respectively, for each target group. This resulted in the following variables: positive stereotyping of Turks $(\alpha=.70)$, positive stereotyping of Germans $(\alpha=.66)$, negative stereotyping of Turks $(\alpha=.65)$, and negative stereotyping of Germans $(\alpha=.61)$.

\section{Results}

\section{Preliminary analyses}

Priming manipulation check Participants closely followed the instructions of the identity priming procedure. The mean number of thoughts listed was 4.30. Independent judges confirmed that participants listed almost exclusively positive $(92 \%)$ aspects of their Turkish or German identity, respectively, and that $97 \%$ of thoughts pertained to the identity requested in experimental instructions.

Intercorrelations among all dependent variables are shown in Table 2. The significance criterion for all analyses to follow is $p<.05$.

Intercorrelations among explicit measures The explicit self-report measures (status, prejudice, evaluation, identification, and stereotyping) showed low to moderate intercorrelations overall, with the signs of significant correlations generally in the expected direction. Overall, higher identification with a given group was associated with less prejudice toward that group, more positive evaluations of that group, etc. Two interesting exceptions should be noted: the more participants identified with their German in-group, the more they ascribed negative stereotypes to Germans $(r=.41)$; also, more positive stereotyping of Turks went along with more prejudiced beliefs about Turks $(r=.46)$ (both $p<.01$ ). These findings suggest that by embracing a given national identity, negative aspects of that identity may come to be endorsed as well.

Implicit measures The correlation between the Turkish SC-IAT and the standard IAT was moderate but significant $(r=.35, p=.003)$ whereas the German SC-IAT was unrelated to the standard IAT $(r=.10, p=.41)$. Interestingly, implicit attitudes toward Germans and Turks, as measured by the SC-IAT, were unrelated overall $(r=.06, p=.60)$. These results speak to the usefulness of a separate assessment of implicit attitudes toward each of the two groups.

Correlations between implicit and explicit measures The SC-IAT and standard IAT scores 


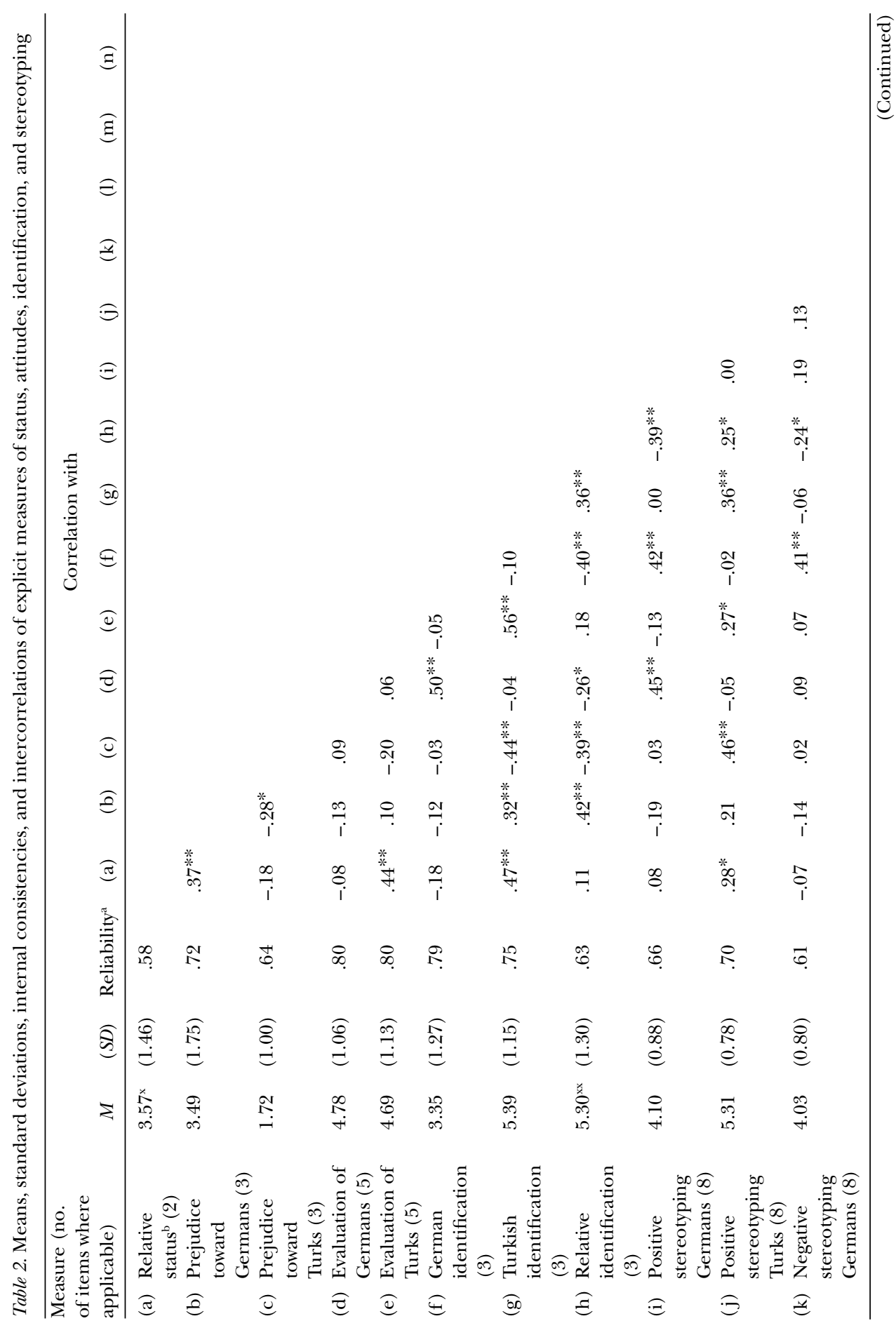




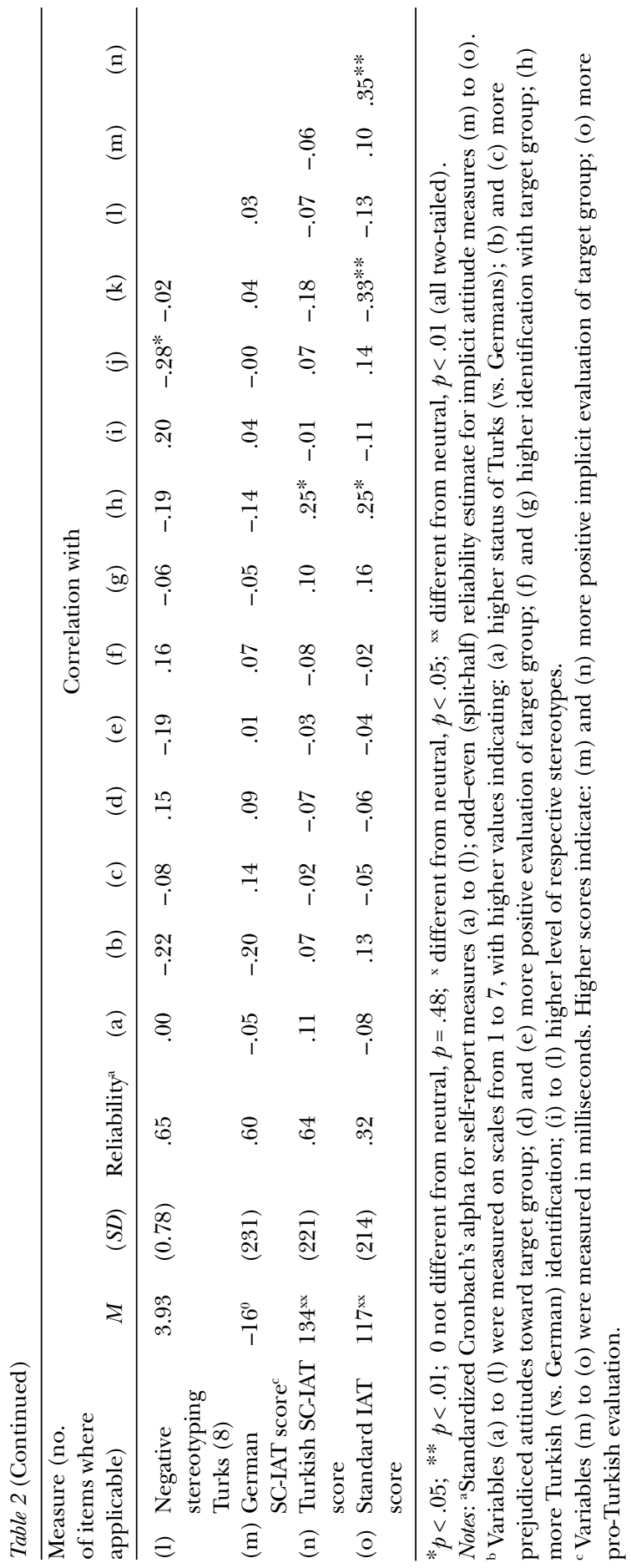


were generally unrelated to explicit measures of perceived status, prejudice, and evaluation. Small but significant correlations were found for both the Turkish SC-IAT and the standard IAT with relative identification (both $r=.25, p<.05)$. Somewhat surprisingly, more pro-Turkish scores on the standard IAT were associated with less negative stereotypes of Germans $(r=-.33, p<.01)$.

\section{Main analyses: Effects of priming and participant sex on the dependent variables}

The hypotheses were tested, and gender effects explored, using 2 (priming: Turkish identity salient vs. German identity salient $) \times 2(\operatorname{sex}$ of participant: male vs. female) between-subjects analysis of variance (ANOVA), and mixed-model $2 \times 2 \times 2$ ANOVAs additionally including target group (Turks vs. Germans) as a repeated-measures factor where applicable.

Implicit attitude measures The Turkish SC-IAT score was significantly larger than zero (grand mean $=134 \mathrm{~ms})(t(70)=4.97, p<.001)$, indicating a positive evaluation overall. In line with Hypothesis 2, a strong effect of identity priming was found: participants were much faster in associating Turkish names with positive than negative words when their Turkish identity had been primed $(M=195 \mathrm{~ms})$ than when their
German identity had been primed ( $M=68 \mathrm{~ms})$ $(F(1,67)=8.05, p=.006)$. This effect was qualified by an interaction of priming and participant $\operatorname{sex}(F(1,67)=3.98, p<.05)$. Simple effects tests revealed that the priming effect was significant for males $(F(1,67)=10.17, p=.002)$, but not for females $(F(1,67)<1)$ (see Figure 1 for means).

The German SC-IAT score did not differ from zero (grand mean $=-16 \mathrm{~ms})(t(70)=-0.72$, $p=.48)$. The ANOVA revealed an opposite pattern compared to the Turkish SC-IAT (see Figure 1 for means), although both the main effect of priming and the interaction of priming and participant sex failed to reach significance (all $p>.11$ ).

A mixed-model ANOVA of both SC-IAT measures, using target as a within-subjects factor, yielded both a significant interaction of priming and target $(F(1,67)=7.55, p=.008)$, and a significant three-way interaction of participant sex, priming, and target $(F(1,67)=6.50, p=.01)$. Follow-up mixed-model analyses were conducted within each sex. For females, this analysis showed only a main effect of target (supporting Hypothesis 1) $(F(1,38)=9.22, p=.004)$ (all other $F<1)$, whereas for males, we found an interaction of priming and target (supporting Hypothesis 2) $(F(1,29)=10.12, p=.003)(F<1$ for the priming main effect). These findings so far suggest that

Single-Category IAT Scores
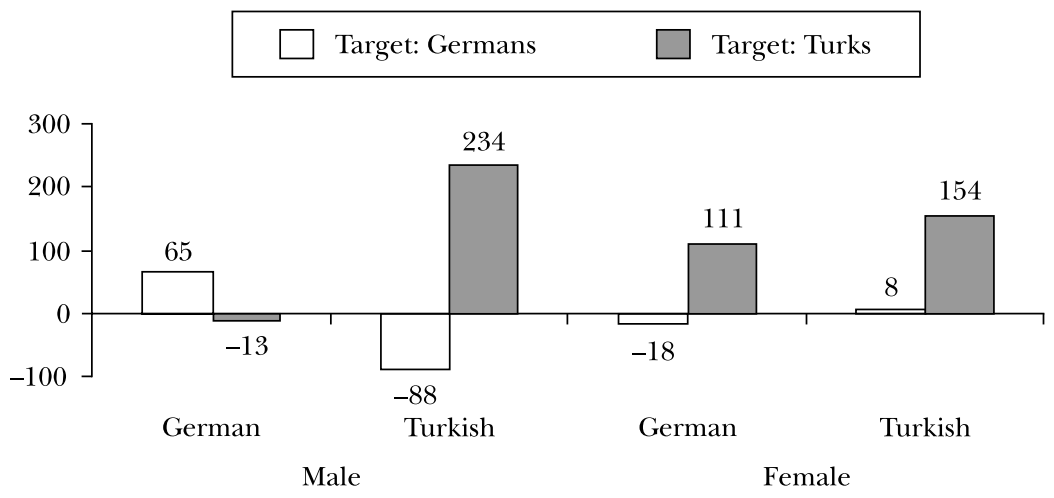

Salient Identity $\times$ Sex of Participant

Figure 1. SC-IAT scores as a function of identity priming and sex of participant. 
males show greater situational flexibility than females in their national identification at an implicit level.

The standard IAT reflected an implicit preference for Turks over Germans (grand mean = $117 \mathrm{~ms}), t(70)=4.77, p<.001$ for the difference from zero, supporting Hypothesis 1. The ANOVA revealed no significant effects of either identity priming or participant sex (all $p>.09)$.

Perceived status, identification, and explicit attitude measures Responses on the status, identification, and explicit attitude measures were mostly unaffected by the priming manipulation. The only significant effect in the $2 \times 2$ ANOVAs was an interaction of priming and sex of participant on the evaluation of Turks $(F(1,67)=4.04, p<.05)$, where females' scores tended to be lower when their German (vs. Turkish) identity had been primed ( $M=4.25$ vs. 4.81), whereas males' scores showed an opposite trend $(\mathrm{M}=5.25$ vs. 4.73$)$. However, neither of the simple effects of priming within levels of sex was significant (both $p>.11$ ).

For the relative measures of perceived status and identification, comparisons of the grand mean with the neutral scale midpoint revealed that participants perceived the status of Turks as lower than that of Germans $(M=3.57)(t(70)=-2.48$, $p=.02)$, suggesting that they experienced being Turkish as a minority identity. At the same time, in line with Hypothesis 1, they identified more strongly with Turks than with Germans $(M=5.30)$ $(t(70)=8.41, p<.001)$.

Also in line with Hypothesis $1,2 \times 2 \times 2$ mixed ANOVAs yielded only main effects of target group on prejudice and identification, showing that participants had lower prejudice against Turks than Germans $(F(1,67)=37.98, p<.001)$, and identified more strongly with Turks than with Germans $(F(1,67)=93.63, p<.001)$ (see Table 2 for means). Neither of these effects was qualified by priming or sex of participant (all $p>.09$ ).

Stereotype measures For only one of the stereotype measures did the $2 \times 2$ ANOVA yield a significant main effect of identity priming: when their German identity had been primed, participants ascribed more negative stereotypic attributes to Turks $(M=4.10)$ than when their Turkish identity had been primed $(M=3.77)$ $(F(1,67)=4.29, p=.04)$; (all other effects $p>.12)$. This result supports Hypothesis 2 for this explicit measure. For the remaining three stereotype measures, no significant effects were found in the $2 \times 2$ ANOVAs (all $p>.21$ ).

A $2 \times 2 \times 2$ mixed ANOVA on the positive stereotypes yielded a main effect of target: In line with Hypothesis 1, participants generally ascribed more positive stereotypic attributes to Turks $(M=5.31)$ than to Germans $(M=4.10)$ $(F(1,67)=67.66, p<.001)$. This effect was not qualified by participant sex or priming (all further $F<1$ ). A $2 \times 2 \times 2$ mixed ANOVA on the negative stereotypes revealed no significant effects (all $p>.07$ ). See Table 2 for means.

\section{Discussion}

\section{Asymmetric effects of identity priming}

The priming of one of two national identities affected people's implicit in-group-related attitudes. This result is in line with our second hypothesis and with previous research, which had shown that implicit attitudes are susceptible to priming effects (Dasgupta \& Greenwald, 2001; Kühnen et al., 2001). Our study extends this line of research by demonstrating that the SC-IAT enables researchers to locate priming effects more precisely by studying the implicit evaluation of separate in-groups. Our results showed that the priming affected the implicit evaluation of participants' dominant (Turkish) group identity more strongly than that of their less dominant (German) group identity. A standard bipolar IAT would not have allowed this distinction to be made, even if it had detected a priming effect (it only showed a nonsignificant trend).

Only two of the explicit measures, both pertaining to Turks as the target group, showed a priming effect: under German (vs. Turkish) identity priming, negative stereotyping of Turks was generally increased, and females (but not males) tended to evaluate Turks less positively. While the stereotyping result is fully in line with Hypothesis 2, we currently have no explanation 
why the priming effect on the evaluation measure is restricted to females, a pattern that runs counter to the gender effect on the SC-IAT (see below). Also, it should be noted that, in terms of variance accounted for, the size of the priming main effect on the Turkish SC-IAT $\left(\eta^{2}=.11\right)$ was about twice as large as the priming main effect on explicit negative stereotyping of Turks $\left(\eta^{2}=.06\right)$ or the priming by sex interaction effect on the evaluation of Turks $\left(\eta^{2}=.05\right)$

Interestingly, however, most of the explicit measures did not show a priming effect at all. One reason for this general absence of a priming effect may be that participants' Turkish identity predominated over their German identity. This preponderance was present on both implicit and explicit indicators, as predicted in Hypothesis 1. Participants were certainly aware of their relative preference for their Turkish identity and may thus have been reluctant to change their responses to the self-report measures in line with the priming. Such effects of self-presentation would not be expected to affect measures of implicit evaluation. This conjecture could be tested in future research by systematically varying self-presentation motives and observing their effects on both implicit and explicit attitudes.

In addition, the explicit and evaluative nature of the priming manipulation, where participants were instructed to list only positive aspects of one identity, might have activated conversational norms that caused participants to refrain from expressing group favoritism on many of the explicit evaluation measures. Having already listed several positive things about their Turkish (or German) identity, participants might have considered it redundant to provide us with such 'old' information again on some of the explicitly evaluative self-report measures (see Bless, Strack, \& Schwarz, 1993; Clark \& Haviland, 1977). This problem might be avoided in future research by using less explicit priming procedures. More importantly, our results suggest that the SC-IAT scores were unaffected by conversational norms, as indeed they should be, assuming that people do not intentionally communicate evaluations when completing the SC-IAT. This points to another strength of the SC-IAT as a measure of group-related attitudes.

\section{Sex differences in the flexibility of group identities?}

We had speculated about general sex differences in self-construals as well as gender-related status differences in the Turkish culture that might lead to male (vs. female) Turks growing up in Germany experiencing greater flexibility in their national identification. Conversely, educational statistics and survey data had suggested that females may show higher motivation to embrace the more egalitarian German culture, resulting in a tendency for females to respond more strongly to the priming manipulation than males. As far as implicit evaluations are concerned, our data are in line with the first possibility: males, but not females, showed clear-cut priming effects in their implicit evaluations of Turks, and a complementary trend in their implicit evaluations of Germans.

It would be highly interesting to examine the replicability and scope of this gender difference. Is it specific to the target group studied, or would it generalize to other immigrant groups? Regarding their status in society, Turkish women in Germany are in a double minority situation. For a Turkish woman, mentally construing herself as a German woman thus means a more extensive change of identity because it entails both a different nationality and a different self-construal in terms of the conventional female role. In other words, the change is from Turkish to German as well as from the role of traditional Muslim woman to the role of egalitarian Western woman. For men, on the other hand, the change in terms of national identity is similar, whereas the construal of the male gender role may not differ as much as the construal of the female gender role between the German and Turkish cultures. If there is in fact greater homogeneity of men's (compared to women's) conventional role and status across cultures, men should generally show greater flexibility in their national identification than women. Further research should address this intriguing possibility. 
The SC-IAT as a single-category measure of implicit group-related attitudes

From a methodological point of view, our results corroborate the usefulness of the SC-IAT as a measure of implicit group-related attitudes. Given the field setting and the relatively small number of trials, our SC-IAT measures of attitudes toward Germans and Turks had an acceptable level of internal consistency. Replicating previous findings (Karpinski \& Steinman, 2006; Wigboldus et al., 2006), they showed only zero to moderate relations, respectively, to an embedded standard IAT that pinpointed the two attitude objects against each other. Furthermore, implicit attitudes toward Turks and Germans, as measured by the SC-IAT, were statistically independent of each other. Thus, forcing participants to implicitly evaluate one attitude object against the other, as is done with the standard IAT, may create an artificial bipolarity that obscures the view on different empirical relations for the two attitude objects of interest. Our data show that this is true not only for in-group versus outgroup attitudes (as was shown by Karpinski \& Steinman, 2006, Study 3), but also for attitudes toward different in-groups.

Our experimental results go beyond previous research by showing that the SC-IAT is suitable for assessing effects of experimental context variations. In this regard, it seems to be a more sensitive measure than the standard IAT. Like most of the explicit attitude and identification measures, the standard IAT indicated a strong pro-Turkish bias that seemed unaffected by experimental condition or sex of participant, whereas the SC-IATs reflected contextual variations (cf. Wigboldus et al., 2006). It should be noted, however, that our design may not have provided ideal conditions for a comparison between SC-IAT and standard IAT. As our methodological focus was on the viability of the SC-IAT, we always assessed the SC-IATs before the standard IAT. Although this is the order recommended by Karpinski and Steinman (2006) for theoretical reasons, it may have affected both the reliability and the context-sensitivity of measures. In future studies using the SC-IAT methodology, a design with counterbalanced order of SC-IAT and standard IAT blocks is thus called for. For the time being, however, we conclude that the SC-IAT appears to be a useful alternative for the assessment of in-group-related attitudes in a non-comparative way.

\section{Notes}

1. We use the term 'national identity' rather than 'ethnic identity' because the latter was distinctly defined for most of our participants, whereas the former term captures what constitutes their dual identity: they all identified to some extent with both Turkish and German national culture, independent of their ethnic background.

2. Four factors with two levels each were varied to counterbalance several methodological aspects of the design. These included the order in which target groups appeared in all measures (Turkish first vs. German first), the valence of the first assignment of a target group in the SC-IAT (with positive vs. negative items), the left-right assignment of evaluative response keys (positive left vs. negative left), and the order in which explicit versus implicit attitudes were assessed (implicit first vs. explicit first). Because these method factors are not of theoretical interest, and because their inclusion would yield extremely small cell sizes, they were not included in analyses and will not be further discussed.

3. From pretests with Turkish and German participants, we selected those items that were clearly positive or negative, were rated as typical of either Turks or Germans, but not both, and whose ratings did not differ between Turkish and German pretest participants. Of the eight positive items, four were stereotypic of Turks ('family-friendly', 'hospitable', 'sociable', 'warm'), and four were stereotypic of Germans ('dependable', 'determined', 'industrious', 'neat'); similarly, of the eight negative items, four were stereotypic of Turks ('aggressive', 'irritable', 'obstinate', 'provoking'), and four were stereotypic of Germans ('boring', 'cagey', 'cold', 'egoistic').

\section{Acknowledgments}

Preparation of this manuscript was facilitated by a grant (415 alechile/ale 02/21671) from the German Academic Exchange Service (DAAD) and the Chilean National Board of Scientific and Technological Research (CONICyT) to Gerd Bohner and Roberto González. Part of 
these data were presented at a meeting of the Transatlantic Research Group on Shared Reality in Communication, Department of Psychology, Columbia University, New York, on 3 December 2004. We thank Friederike Eyssel and Malte Friese for helpful comments on a previous draft, as well as Fatma Akkaya-Willis, Christian Glass, Heike Gerger, Hanna Kley, Justine Patrzek, Matthias Rohde, Saskia Sabelus, and Lily-Maria Silny for their help in the preparation of materials, data collection, and analysis.

\section{References}

Ataca, B., \& Berry, J. W. (2002). Psychological, sociocultural, and marital adaptation of Turkish immigrant couples in Canada. International Journal of Psychology, 37, 13-26.

Baumeister, R. F., \& Sommer, K. L. (1997). What do men want? Gender differences and two spheres of belongingness: Comment on Cross and Madson (1997). Psychological Bulletin, 122, 38-44.

Beauftragte der Bundesregierung für Migration, Flüchtlinge und Integration (2004). Daten, Fakten, Trends: Strukturdaten der ausländischen Bevölkerung [Data, facts, and trends: Structural data on the immigrant population]. Bonn, Germany: Bundesbeauftragte. [Available online: http://www.integrationsbeauftragte.de/ download/Strukturdaten.pdf]

Berry, J. W. (1984). Cultural relations in plural societies: Alternatives to segregation and their sociopsychological implications. In N. Miller \& M. B. Brewer (Eds.), Groups in contact: The psychology of desegregation. New York: Academic Press.

Berry, J. W. (1999). Intercultural relations in plural societies. Canadian Psychology, 40, 12-21.

Berry, J. W., Phinney, J. S., Sam, D. L., \& Vedder, P. (2006). Immigrant youth: Acculturation, identity, and adaptation. Applied Psychology: An International Review, 55, 303-332.

Blair, I. V. (2002). The malleability of automatic stereotypes and prejudice. Personality and Social Psychology Review, 6, 242-261.

Bless, H., Strack, F., \& Schwarz, N. (1993). The informative functions of research procedures: Bias and the logic of conversation. European Journal of Social Psychology, 23, 149-165.

Clark, H. H., \& Haviland, S. (1977). Comprehension of the given-new contract. In R. Freedle (Ed.), Discourse production and comprehension (pp. 1-40). Hillsdale, NJ: Erlbaum.
Cota, A. A., \& Dion, K. L. (1986). Salience of gender and sex composition of ad hoc groups: An experimental test of distinctiveness theory. Journal of Personality and Social Psychology, 50, $770-776$.

Cross, S. E., \& Madson, L. (1997). Models of the self: Self-construals and gender. Psychological Bulletin, 122, 5-37.

Dasgupta, N., \& Greenwald, A. G. (2001). On the malleability of automatic attitudes: Combating automatic prejudice with images of admired and disliked individuals. Journal of Personality and Social Psychology, 81, 800-814.

Fazio, R. H., \& Olson, M. A. (2003). Implicit measures in social cognition research: Their meaning and use. Annual Review of Psychology, 54, 297-327.

Fiske, S. T. (1998). Stereotyping, prejudice, and discrimination. In D. Gilbert, S. T. Fiske, \& G. Lindzey (Eds.), Handbook of social psychology (4th ed., Vol. 2, pp. 357-411). New York: McGraw-Hill.

González, R., \& Brown, R. (2003). Generalization of positive attitude as a function of subgroup and superordinate group identifications in intergroup contact. European Journal of Social Psychology, 33, 195-214.

González, R., \& Brown, R. (2006). Dual identities in intergroup contact: Group status and size moderate the generalization of positive attitude change. Journal of Experimental Social Psychology, 42, 753-767.

Greenwald, A. G. (2001). Health of the implicit association test at age 3. Zeitschrift für Experimentelle Psychologie, 48, 85-93.

Greenwald, A. G., McGhee, D. E., \& Schwartz, J. L. K. (1998). Measuring individual differences in implicit cognition: The implicit association test. Journal of Personality and Social Psychology, 74, 1464-1480.

Haye, A., González, R., Ordóñez, G., Bohner, G., Siebler, F., Sirlopú, D. et al. (2007). Systemperpetuating asymmetries between conscious and unconscious intergroup attitudes among indigenous and non-indigenous Chileans. Manuscript under review.

Hewstone, M., Rubin, M., \& Willis, H. (2002). Intergroup bias. Annual Review of Psychology, 53, 575-604.

Hofmann, W., Gawronski, B., Gschwendner, T., Le, H., \& Schmitt, M. (2005). A meta analysis on the correlation between the Implicit Association Test and explicit self report measures. Personality and Social Psychology Bulletin, 31, 1369-1385. 
Hornsey, M. J., \& Hogg, M. A. (2000). Assimilation and diversity: An integrative model of subgroup relations. Personality and Social Psychology Review, 4, 143-156.

Karpinski, A., \& Steinman, R. B. (2006). The single category implicit association test as a measure of implicit social cognition. Journal of Personality and Social Psychology, 91, 16-32.

Kühnen, U., Schiessl, M., Bauer, N., Paulig, N., Pohlmann, C., \& Schmidthals, K. (2001). How robust is the IAT? Measuring and manipulating implicit attitudes of East and West Germans. Zeitschrift für Experimentelle Psychologie, 48, 135-144.

McGuire, W. J., McGuire, C. V., Child, P., \& Fujioka, T. (1978). Salience of ethnicity in the spontaneous self-concept as a function of one's ethnic distinctiveness in the social environment. Journal of Personality and Social Psychology, 36, 511-520.

Mummendey, A., \& Otten, S. (1998). Positivenegative asymmetry in social discrimination. European Review of Social Psychology, 9, 107-143.

Nosek, B. A., Greenwald, A. G., \& Banaji, M. R. (2006). The implicit association test at age 7: A methodological and conceptual review. In J. A. Bargh (Ed.), Social psychology and the unconscious: The automaticity of higher mental processes (pp. 265-292). New York: Psychology Press.

Pettigrew, T. F., \& Meertens, R. W. (1995). Subtle and blatant prejudice in western Europe. European Journal of Social Psychology, 25, 57-75.

Polat, Ü. (1998). Soziale und kulturelle Identität türkischer Migranten der zweiten Generation in Deutschland [Social and cultural identity of Turkish migrants of the second generation in Germany]. Hamburg: Kovac.

Rudman, L. A. (2004). Sources of implicit attitudes. Current Directions in Psychological Science, 13, 79-82.

Rudman, L. A., Ashmore, R. D., \& Gary, M. L. (2001). 'Unlearning' automatic biases: The malleability of implicit prejudice and stereotypes. Journal of Personality and Social Psychology, 81, 856-868.

Rudman, L. A., \& Heppen, J. B. (2003). Implicit romantic fantasies and women's interest in personal power: A glass slipper effect? Personality and Social Psychology Bulletin, 29, 1357-1370.

Schmukle, S. C., \& Egloff, B. (2005). A latent statetrait analysis of implicit and explicit personality measures. European Journal of Psychological Assessment, 21, 100-107.

Schwarz, N., \& Bohner, G. (2001). The construction of attitudes. In A. Tesser \& N. Schwarz (Eds.), Blackwell handbook of social psychology: Vol. 1. Intraindividual processes (pp. 436-457). Oxford, UK: Blackwell.

Şen, F. (1999). Zur 40jährigen Geschichte der türkischen Migranten [On the 40-year history of Turkish migrants]. In G. Berger \& P. Hartmann (Eds.), Soziologie in konstruktiver Absicht: Festschrift für Günter Endruweit [Sociology with constructive intent: Anniversary publication for Günter Endruweit] (pp. 255-282). Hamburg: Knut Reim.

Şen, F., \& Wierth, A. (1992). 1961-1991: Ein kritischer Rückblick auf die dreißigjährige Migrationsgeschichte der Türken in der Bundesrepublik Deutschland [1961-1991: A critical look back on the thirty-year migration history of Turks in the Federal Republic of Germany]. Zeitschrift für Ausländerrecht und Ausländerpolitik, 12, 75-80.

Sidanius, J., Pratto, F., \& Rabinowitz, J. L. (1994). Gender, ethnic status, and ideological asymmetry: A social dominance interpretation. Journal of Cross-Cultural Psychology, 25, 194-216.

Siebler, F., González, R., Ordóñez, G., Bohner, G., Haye, A., Sirlopú, D. et al. (2007). The category-focus implicit association test. Manuscript under review.

Strack, F., \& Deutsch, R. (2004). Reflective and impulsive determinants of social behavior. Personality and Social Psychology Review, 8, 220-247.

Tajfel, H., \& Turner, J. (1986). The social identity theory of intergroup behavior. In S. Worchel \& W. Austin (Eds.), Psychology of intergroup relations (pp. 7-24). Chicago: Nelson-Hall.

United Nations (2005). Human development report 2005. New York: United Nations Development Program. [Available online: http://hdr.undp. org/reports/global/2005/pdf/HDR05_ complete.pdf]

Webb, E. J., Campbell, D. T., Schwartz, R. D., Sechrest, L., \& Grove, J. B. (1981). Nonreactive measures in the social sciences (2nd ed.). Boston: Houghton Mifflin.

Wigboldus, D. H. J., Holland, R. W., \& van Knippenberg, A. (2006). Single-target implicit associations. Unpublished manuscript.

Wilson, T. D., Lindsey, S., \& Schooler, T. Y. (2000). A model of dual attitudes. Psychological Review, $107,101-126$. 
Wittenbrink, B., Judd, C. M., \& Park, B. (2001). Spontaneous prejudice in context: Variability in automatically activated attitudes. Journal of Personality and Social Psychology, 81, 815-827.

Paper received 17 April 2006; revised version accepted 19 October 2007.

\section{Biographical notes}

GERD BOHNER is professor of social psychology in the department of psychology at the University of Bielefeld, Germany. His research interests include attitudes, persuasion, social influence, gender-related violence, and intergroup relations.

FRANK SIEBLER is associate professor in the department of psychology at the University of Troms $\varnothing$, Norway. His research interests include the interplay of implicit and explicit forms of social information processing, as well as computer models of social cognition.

ROBERTO GONZÁLEZ is associate professor in the department of psychology at Pontifica Universidad Católica de Chile. His research interests include intergroup relations, prejudice, intergroup contact, social identity, and attitude change.

ANDRÉS HAYE is associate professor in the department of psychology at Pontifica Universidad Católica de Chile. His research interests include attitudes, prejudice, memory, discourse, social interaction, and ideology.

EIKE A. SCHMidT is a PhD student at the HeinrichHeine-University of Düsseldorf, Germany, and is currently working on his thesis in the field of applied neurophysiology and ergonomics. 